\title{
Survey of Harmonics Measurements in Electrical Distribution Systems
}

\author{
Leon M. Tolbert, Member, IEEE \\ Oak Ridge National Laboratory* \\ P.O. Box 2008, Bldg 1000 \\ Oak Ridge, TN 37831-6334 \\ Phone: (423) 576-8175 \\ FAX: (423) 576-8189 \\ e-mail: tolbertlm@ornl.gov
}

\author{
Harold D. Hollis and Peyton S. Hale, Jr. \\ U.S. Army Center for Public Works, CECPW-K \\ 7701 Telegraph Drive \\ Alexandria, VA 22315-3862 \\ Phone: (703) 428-8191 \\ FAX: (703) 428-8297 \\ e-mail: Peyton.S.Hale@cpw01.usace.army.mil
}

\begin{abstract}
An assessment of the harmonics found in the electrical distribution system of several buildings in the three Department of Energy (DOE) Oak Ridge plants in Tennessee has yielded several conclusions useful in the design of electrical distribution systems. A preliminary survey to determine where significant amounts of harmonic currents or voltages existed in the distribution system was performed at several buildings by comparing readings taken with true root-mean-square (RMS) multimeters and averaging multimeters (non-true RMS meters). From these measurements and subsequent calculations, facilities that appeared to have significant levels of harmonics present were analyzed with a power analyzer that could record waveforms and give the spectrum and magnitude of harmonics. Among the non-linear loads for which sample waveforms are illustrated are fluorescent lighting (both magnetic and electronic ballasts), variable frequency drives, switch mode power supplies, and uninterruptible power supplies. A discussion as to how various harmonic waveforms come about as a result of these nonlinear loads is also outlined in this paper.
\end{abstract}

\section{INTRODUCTION}

A harmonic survey was done for all of the $120 / 208 \mathrm{~V}$ and $120 / 240 \mathrm{~V}$ branch circuit panels in 31 buildings at the three Department of Energy (DOE) Oak Ridge plants. The buildings ranged in age from 5 to 50 years old. Some of the building uses include office space, computer and control centers, laboratory instrumentation, robotic manipulators, Xray equipment, furnaces, and maintenance shops. This paper outlines a quick method of identifying harmonic currents in an electrical distribution system and assessing where they originate and to what extent the harmonic currents should be suppressed.

Because most electrical systems were designed for linear voltage and current waveforms (i.e. nearly sinusoidal), excessive non-linear loads can cause serious problems such as overheating conductors or transformers, capacitor failures, inadvertent circuit breaker tripping, or malfunction of electronic equipment [1,2]. Nonlinear currents can originate from any of three causes: 1 . nonsinusoidal generation of voltage, 2. nonlinear devices used in the transportation of electrical energy, 3. nonlinear load devices. The voltage waveforms generated by utilities and then stepped up to a transmission voltage level generally are very close to sinusoidal and have little distortion. Transmission lines, cables, and transformers are transportation devices which are quite linear in nature and cause little distortion to voltage or current waveforms. However, variable frequency drives and uninterruptible power supplies which use electronic devices to rectify ac to dc and then invert back to ac are nonlinear transportation devices. Several loads are nonlinear such as switch mode power supplies [3,4] and fluorescent light ballasts $[5,6]$.

\section{BACKGROUND}

Through Fourier analysis, any nonsinusoidal periodic waveform can be represented as the sum of a dc component and sine waves of various amplitudes and phase displacement from some relative angle. The sine waves all have frequencies which are an integer multiple of some fundamental frequency, which in the United States is $60 \mathrm{~Hz}$. Any periodic voltage waveform $V(t)$ can be expressed as the sum of a dc component $\mathrm{V}_{0}$ and sine waves with a fundamental frequency $\omega(60 \mathrm{~Hz})$ :

$$
V(t)=V_{o}+\sum_{h=1}^{N} V_{h} \sin \left(h \omega t+\theta_{h}\right)
$$

A similar equation could be written for a current waveform $I(t)$. Because these individual sine waves are all integer multiples of a fundamental frequency, they are called harmonics. The harmonic order is defined as the integer multiple of the fundamental. For example, a $180 \mathrm{~Hz}$ harmonic frequency wave on a $60 \mathrm{~Hz}$ source would be called the 3rd harmonic. Equation (2) shows how to find the root-mean square (RMS) value of a current waveform where the RMS value of each of the harmonics, $I_{h}$, is known.

* Prepared by the Oak Ridge National Laboratory, Oak Ridge, Tennessee, 37831-6334, managed by Lockheed Martin Energy Research, Inc. for the U.S. Department of Energy under contract DE-AC05-96OR22464. The submitted manuscript has been authored by a contractor of the U.S. Government. Accordingly, the U.S. Government retains a nonexclusive, royalty-free license to publish or reproduce the published from of this contribution, or allow others to do so, for U.S. Government purposes. 


$$
I_{R M S}=\left[\sum_{h=1}^{N}\left(I_{h}\right)^{2}\right]^{I / 2}
$$

One measure of the nonlinearity, or distortion, in a waveform is given by (3) and called total harmonic distortion (THD). THD is the ratio of the RMS value of the total harmonic currents (nonfundamental part of the waveform) and the RMS value of the fundamental portion, $I_{1}$, of the waveform. This value is usually expressed as a percentage of the fundamental current.

$$
T H D=\frac{\left[\sum_{h=2}^{N}\left(I_{h}\right)^{2}\right]^{1 / 2}}{I_{l}}
$$

Two other measures of distortion are the crest factor and the form factor. The crest factor is the ratio of the peak of a waveform to its RMS value. For a linear sinusoidal waveform, the crest factor would be the square root of 2, or 1.414.

$$
\text { Crest_Factor }=\frac{I_{\text {peak }}}{I_{\text {RMS }}}
$$

The form factor, or distortion factor, is the ratio of the RMS value of a waveform to the RMS of the waveform's fundamental value, $I_{1}$. For a linear sinusoidal waveform, the form factor would be 1.0 [7].

$$
\text { Form_ Factor }=\frac{I_{R M S}}{I_{1}}
$$

Symmetrical components is a mathematical tool used to analyze power systems. Harmonic orders can be divided into positive, negative, and zero sequence components [8]. Positive sequence components are the given phase order and include the following harmonic orders: 1st (fundamental), 4th, 7th, 10th, etc. Negative sequence components are reverse phase order and include the following harmonic orders: 2 nd, 5 th, 8th, 11th, etc. Zero sequence components have all three components in phase and include the following harmonic orders: 3rd, 6th, 9th, 12th, etc. Phase and amplitude balanced positive and negative sequence components sum to zero in the neutral or ground. Balanced zero sequence components, however, add in the neutral or ground. Because the zero sequence harmonics are divisible by 3 , they are referred to as triplens.

\section{RMS vS. NON-RMS MEASUREMENTS}

\section{A. Different Meter Types}

Fig. 1 is a chart comparing the measured values for various waveforms using peak, averaging, and true-RMS calibrated meters [9]. For the preliminary harmonic survey to determine where significant amounts of harmonic current existed in the $120 / 208 \mathrm{~V}$ and 120/240 V electrical distribution systems at the three Department of Energy (DOE) Oak Ridge plants, measurements were taken for branch circuit panels in 31 buildings with true-RMS calibrated multimeters and averaging (non-true RMS) calibrated multimeters [10].
Fig. 1. Comparison of conversion techniques for AC current measurements. All readings are normalized to read $100 \mathrm{~A}$ on an average, converting, RMScalibrated meter - the most common type of meter.

Two measurements of voltage, true-RMS and peak (or amplitude), and three measurements of current, true RMS, average, and peak with a true-RMS meter, were taken at several panelboards in the DOE facilities. The averaging meters used considered the fundamental portion of the waveform only and ignored harmonics. For nonlinear loads with substantial harmonic distortion present, the difference in the measurements between the averaging and true-RMS meters was notable, and the form factor computed from (5) was on the order of 1.2 to 1.5 instead of 1.0 as is the case for linear loads. Additionally, the crest factor computed from (4), which used the true-RMS and peak measurements from the RMS-calibrated meter, was on the order of 2 or 3 for waveforms with significant harmonic content instead of close to 1.4 as would be the case for a sinusoidal wave.

\section{B. Crest and Distortion Factors}

From the measurements made on these panels, the distortion factor and crest factor were calculated for each of the phase and neutral voltages and currents. Of the 200 panels surveyed, 72 had phase current crest factors greater than 2.0 or current distortion factors greater than 1.5.

The distribution of voltage crest factors is shown in Fig. 2. Seventy-five percent of the voltage crest factors were between 1.36 and 1.39 , with an average crest factor of 1.376 for the 506 different calculations. In fact, only $3 \%$ of the voltage crest factors did not fall within the range of 1.34 to 1.43 . The 


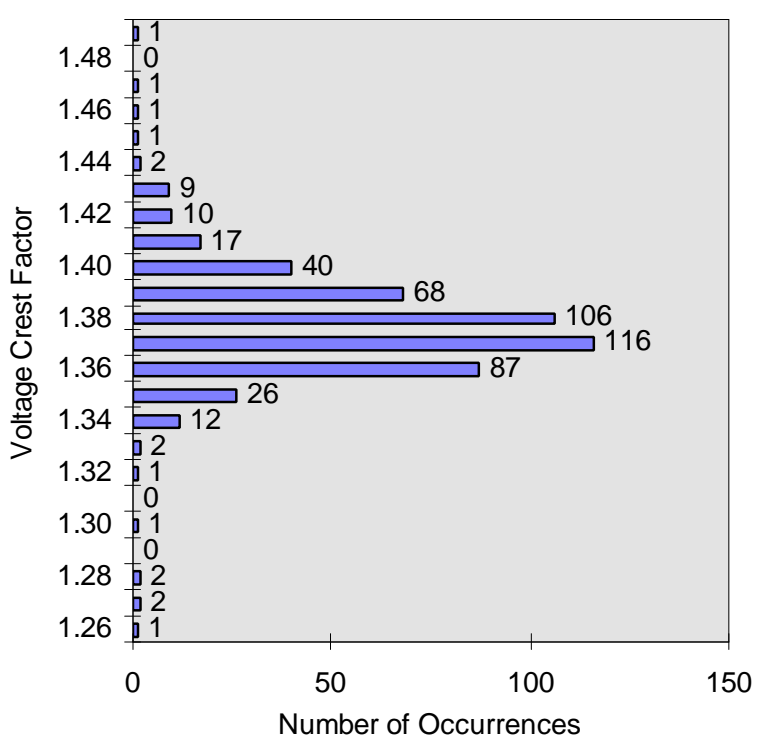

Fig. 2. Mathematical distribution of phase voltage crest factors.

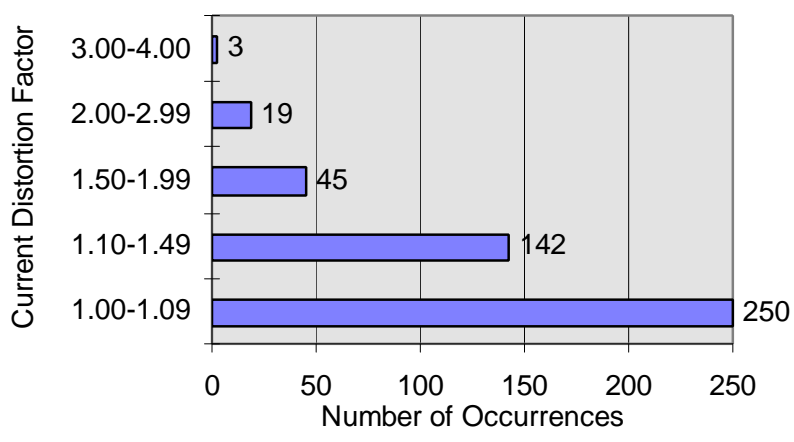

Fig. 3. Mathematical distribution of phase current distortion factors.

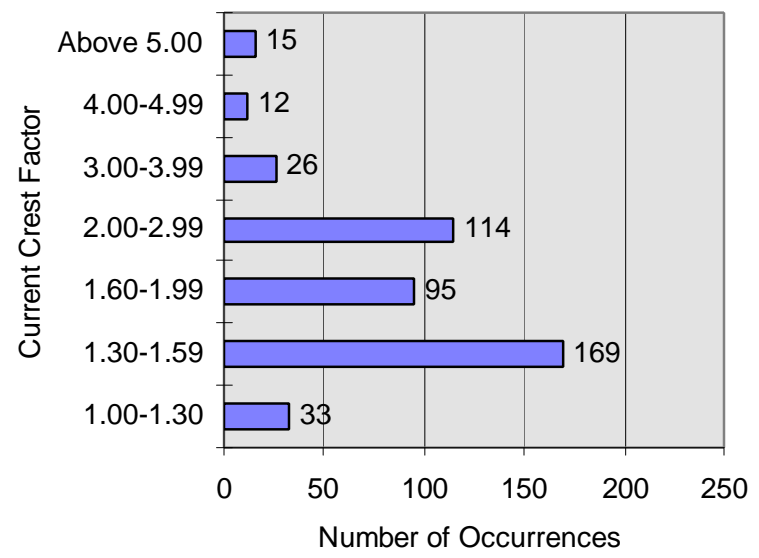

Fig. 4. Mathematical distribution of phase current crest factors.

minimum voltage crest factor and the maximum voltage crest factor calculated were 1.26 and 1.49 , respectively. For panels that had current crest factors greater than 2.0, the voltage crest factor averaged 1.371, and for the remaining panels the crest factor averaged 1.380. These calculations show that panels with high amounts of current harmonics tend to cause

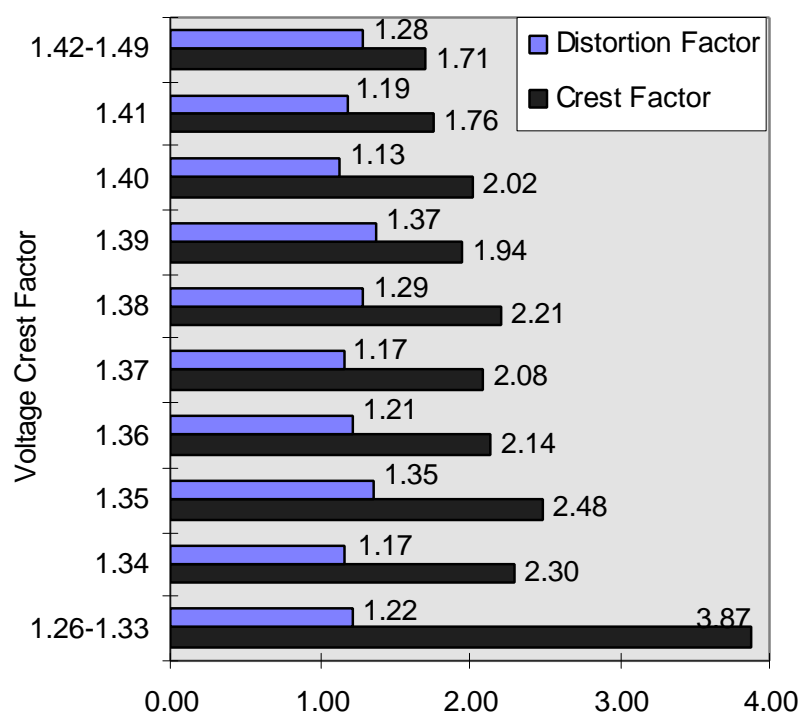

Fig. 5. Average current distortion and crest factor for each voltage crest factor.

the voltage at the panel to have more of a flat-topped voltage waveform.

The distribution of current distortion factors and current crest factors are shown in Figs. 3 and 4, respectively. The current distortion factor was minimal (less than 1.1) for more than $54 \%$ of the 459 current measurements made at the power panels. However, $15 \%$ of the conductors checked had current distortion factors which exceeded 1.50. Current crest factors exceeded 2.00 for $36 \%$ of the conductors surveyed, and 15 instances were found where the crest factor exceeded 5.00.

To help illustrate the interrelation between the voltage distortion and the current distortion, a bar chart is shown in Fig. 5 which plots the average values for the current distortion factor and current crest factor for each of the voltage crest factors calculated. From Fig. 5, one can see that the average current distortion factor and voltage crest factor really have no interrelationship. However, the average current crest factor is generally higher for the lower voltage crest factor. A high current crest factor load usually draws a large current pulse near the peak of the voltage waveform. The subsequent voltage drop causes a flat-topping of the voltage waveform, hence a lower voltage crest factor.

\section{Power Analyzer Measurements}

Several panels in the facilities that had high crest or distortion factors and had a load of more than 30 A were chosen to have measurements made with an 8 channel power analyzer that takes simultaneous snapshots of the voltage and current waveforms for all three phases and neutral of a 3phase system. The analyzer also could compute the spectrum and magnitude of harmonics for these various waveforms. Using multimeters to screen candidate panels first saved several days of work because they are much more easily and quickly connected and disconnected from a power panel's main conductors. In addition, the power analyzer required an 
external source of $120 \mathrm{~V}$ ac power which sometimes was not readily available.

The voltage THD for all of the panels surveyed with the power analyzer was between $2.0 \%$ and $4.5 \%$. This meets the $5.0 \%$ voltage THD limit for end use loads recommended by IEEE 519 [11]. Most of the distortion was due to 3rd and 5th harmonics. The voltage distortion was greater at the panels that had the greatest current distortions (greater than $50 \%$ THD). This data lends credence to the fact that current harmonics do effect voltage THD. The voltage produced by current harmonics can be characterized as

$$
V=\sum_{h=2}^{N} I_{h}\left(R_{h}+j h \omega L_{h}\right) .
$$

However, this effect is usually slight when compared to electrical equipment which generate or synthesize voltage waveforms.

\section{IDENTIFICATION OF HARMONICS}

From the more than 1000 sample waveforms collected throughout the buildings, several different sources of harmonic currents and voltages were identified in the DOE complex. A sample of the different waveforms found during the survey along with an identification of the source of the harmonic current or voltage follows. References [11-13] illustrate waveforms for some additional non-linear loads.

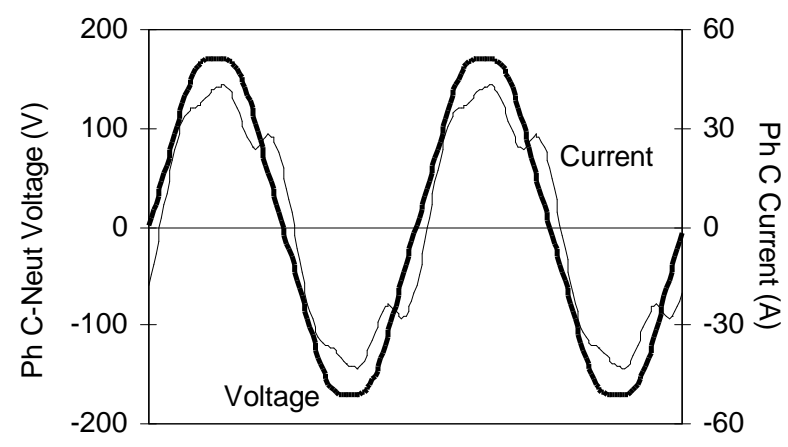

(a)

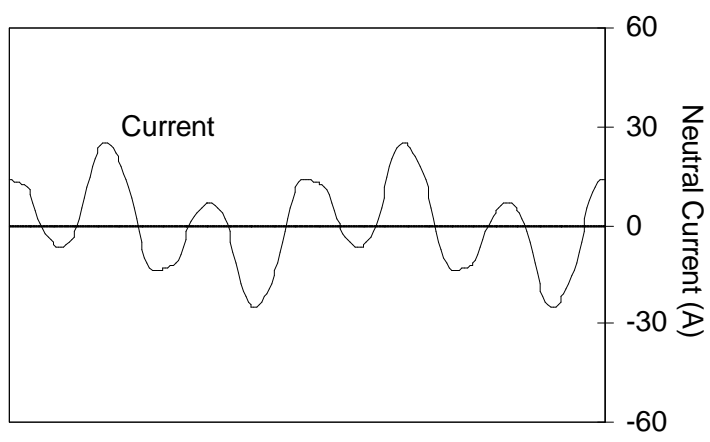

(b)

Fig. 6. Waveforms for magnetic ballasts. (a) Phase voltage and current. (b) Neutral current for a three phase, four wire system.

\section{A. Fluorescent Lighting}

Measurements were taken at an office building at the Oak Ridge National Laboratory to get representative data samples for traditional magnetic fluorescent ballasts and T-12 lamps. These ballasts were then removed and replaced with new electronic ballasts and T-8 lamps and new measurements then taken.

Fig. 6 depicts the phase voltage and current and the neutral current for a lighting panel which had a load consisting entirely of fluorescent lights with magnetic ballasts. The harmonics in the current waveform are caused by the nonlinearity of the lamp arc itself in series with the ballast [5]. The THD for the phase currents was $13.9 \%$ and for the neutral currents was $141.3 \%$. The spectrum consisted of only odd harmonics and ranged from the $3 \mathrm{rd}$ to the $17 \mathrm{th}$. In addition, the amplitude of the individual harmonics for the 9 th through the 17 th were all less than $1 \%$ of the amplitude of the fundamental $(60 \mathrm{~Hz})$.

Fig. 7 depicts the phase voltage and current and the neutral current for the same lighting panel after all of the fluorescent lights were converted to electronic ballasts. With the new ballasts, the panel had a phase current THD of $17.2 \%$ and $85.3 \%$ THD for the neutral current. Unlike the magnetic ballasts, the electronic ballasts had individual harmonics at frequencies up to the 33rd harmonic $(1980 \mathrm{~Hz})$ which had

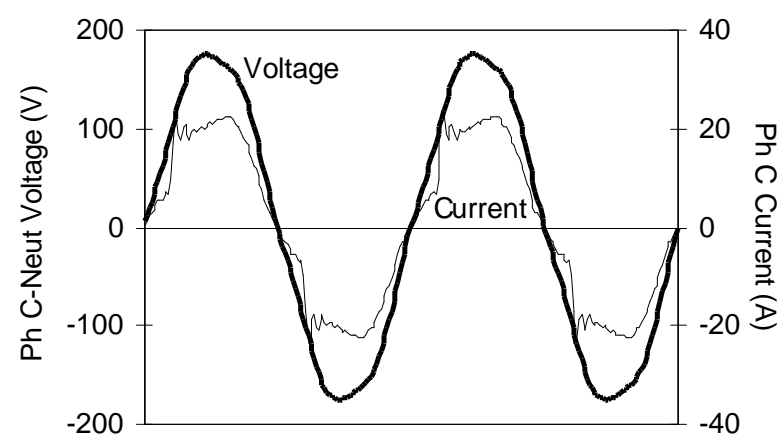

(a)

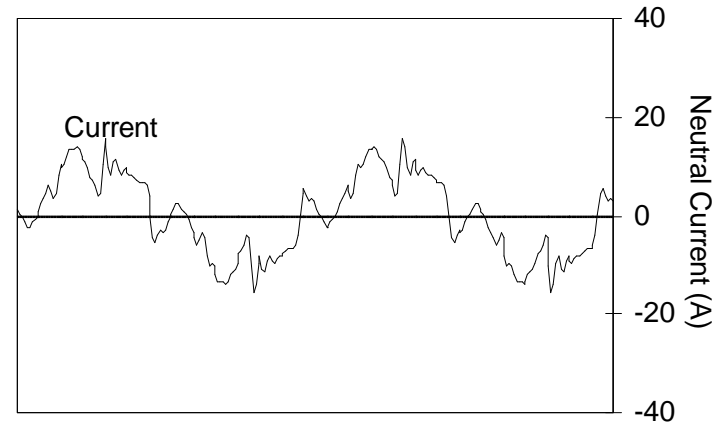

(b)

Fig. 7. Waveforms for electronic ballasts. (a) Phase voltage and current. (b) Neutral current for a three phase, four wire system. 
TABLE I.

HARMONIC SPECTRUM FOR FlUORESCENT Light BALLASTS

\begin{tabular}{||l|c|c|c|c||}
\hline \multirow{2}{*}{ Harmonic } & \multicolumn{2}{|c|}{ Magnetic Ballast } & \multicolumn{2}{c||}{ Electronic Ballast } \\
\cline { 2 - 5 } & Phase & Neutral & Phase & Neutral \\
\hline Current THD & 12.8 & 171.2 & 16.3 & 44.0 \\
\hline 3rd & 10.6 & 169.8 & 3.6 & 11.9 \\
\hline 5 th & 6.7 & 16.6 & 11.7 & 31.6 \\
\hline 7th & 1.6 & 3.3 & 5.2 & 3.7 \\
\hline 9th & 0.8 & 12.7 & 3.9 & 20.1 \\
\hline 11th & 0.2 & 2.3 & 3.5 & 2.0 \\
\hline 13th & 0.3 & 2.5 & 3.4 & 4.1 \\
\hline 15th & 0.1 & 3.4 & 2.1 & 10.1 \\
\hline 17th & 0.1 & 0.0 & 2.1 & 3.2 \\
\hline 19th & 0.0 & 0.7 & 2.2 & 3.1 \\
\hline 21st & 0.0 & 0.5 & 2.0 & 9.6 \\
\hline 23rd & 0.0 & 0.0 & 1.7 & 1.5 \\
\hline 25th & 0.0 & 0.4 & 1.9 & 3.7 \\
\hline 27th & 0.0 & 0.0 & 1.7 & 8.2 \\
\hline 29th & 0.0 & 0.0 & 1.5 & 3.0 \\
\hline 31st & 0.0 & 0.0 & 1.5 & 3.5 \\
\hline 33rd & 0.0 & 0.0 & 1.4 & 6.4 \\
\hline Voltage THD & 2.7 & & 3.7 & \\
\hline 3rd & 0.6 & & 0.4 & \\
\hline 5th & 2.6 & & 3.7 & \\
\hline 7 th & 0.3 & & 0.3 & \\
\hline 9th & 0.0 & & 0.2 & \\
\hline 11th & 0.0 & & 0.1 & \\
\hline \hline
\end{tabular}

magnitudes of between 1.4 and 3 percent of the fundamental.

Table I is a compilation of the harmonic components of current and voltage for the magnetic and electronic ballasts surveyed. The voltage THD for the magnetic ballasts averaged $2.67 \%$ THD with almost all of the distortion due to a fifth harmonic component. With the electronic ballasts, the voltage THD at the lighting panel averaged $3.70 \%$ THD with most of the distortion due to a fifth harmonic component. The increase in voltage distortion is directly correlated to the increase in fifth harmonic current distortion. The fifth harmonic content of the current increased by $73.4 \%$ when the magnetic ballasts were replaced by electronic ballasts.

\section{B. Variable Frequency Drives}

Sample waveforms for the voltage and current on the line and load side of a variable frequency drive (VFD) at a building in the Y-12 plant appear in Fig. 8. Note in Fig. 8a, that the VFD draws two current pulses for each half cycle of the voltage waveform. This is typical of most VFD's which employ six pulse conversion to commutate the three-phase line voltage to a DC voltage [7]. Six pulse converters have two switches per phase; this accounts for the two current pulses during each half cycle of the voltage waveform as shown in Fig. 8a. The current is discontinuous, i.e. goes to

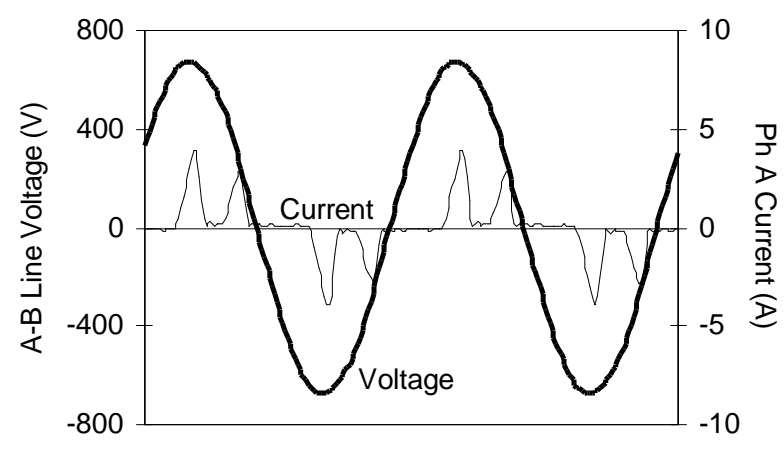

(a)

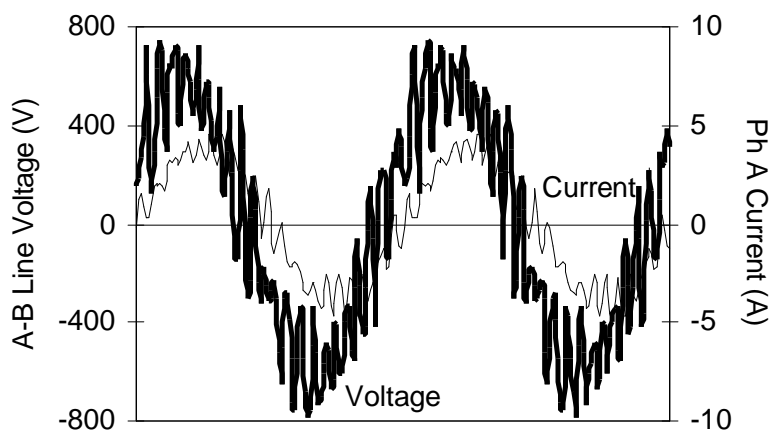

(b)

Fig. 8. Variable frequency drive (a) line and (b) load side waveforms.

zero during each half cycle, because this particular VFD does not have any line inductors.

This particular VFD used a pulse width modulation (PWM) switching scheme in order to invert the voltage from its dc bus into a sinusoidal output. The PWM output of the VFD was a voltage waveform that was quite noisy. The power analyzer captured this phenomenon for the voltage waveform only because the VFD surveyed had a sufficiently low switching frequency (only about $500 \mathrm{~Hz}$ ). State of the art low power VFDs have switching frequencies between 10 and 20 $\mathrm{kHz}$, and most power analyzers would not capture the switching noise from these VFDs because they sample only up to between 2 and $3 \mathrm{kHz}$.

\section{Switch Mode Power Supplies}

A switch mode power supply has a large capacitor in it (Fig. 9) which maintains a near-constant voltage for the DC bus in the power supply. The capacitor is charged (and draws current) only during the peak of the voltage waveform as shown in Fig. 10; hence the large current pulse at the peak of the voltage waveform [10]. In Fig. 10a, the current waveform for a power panel at ORNL which fed receptacles in offices that had large amounts of equipment that used switch mode power supplies is depicted.

In three-phase systems that have a neutral conductor and a large number of single phase switch mode power supply 


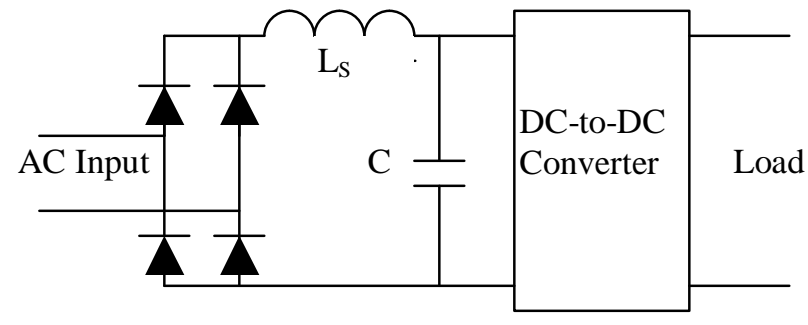

Fig. 9. Ordinary switch mode power supply circuit schematic.

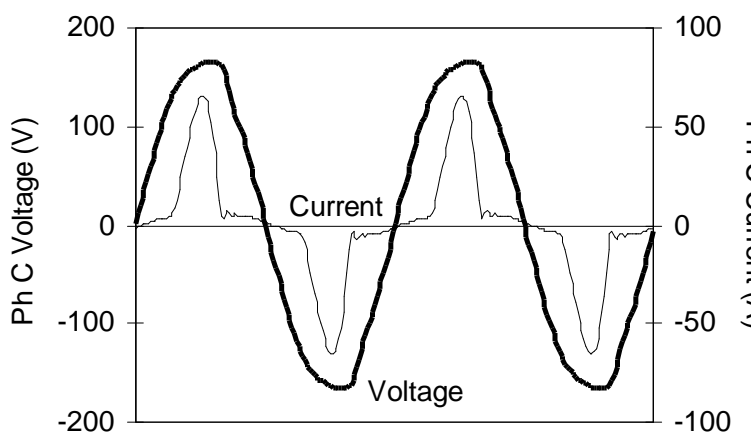

(a)

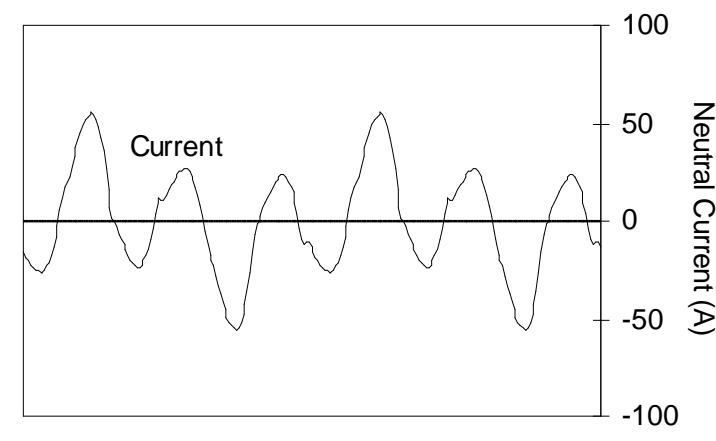

(b)

Fig. 10. Switch mode power supply waveforms. (a) Voltage and current for one phase of a three phase 120/208 V system. (b) Neutral current.

loads, the neutral conductor will carry a large percentage of each of the three phase conductors' current even under balanced load conditions. This is because switch mode power supplies draw a current which has a significant amount of triplen harmonics (3rd, 9th, 15th, etc.) Triplen harmonics are zero sequence harmonics which add in the neutral instead of canceling like positive sequence (1st, 7th, 13th, etc.) and negative sequence (5th, 11th, 17th, etc.). The sample waveform shown in Fig. 10b indicates that the neutral current is mostly $180 \mathrm{~Hz}$ (3rd harmonic).

\section{Uninterruptible Power Supplies}

Sample waveforms for the voltage and current on the line and load side of an uninterruptible power supply (UPS) located in a building at the Y-12 plant appear in Fig. 11.
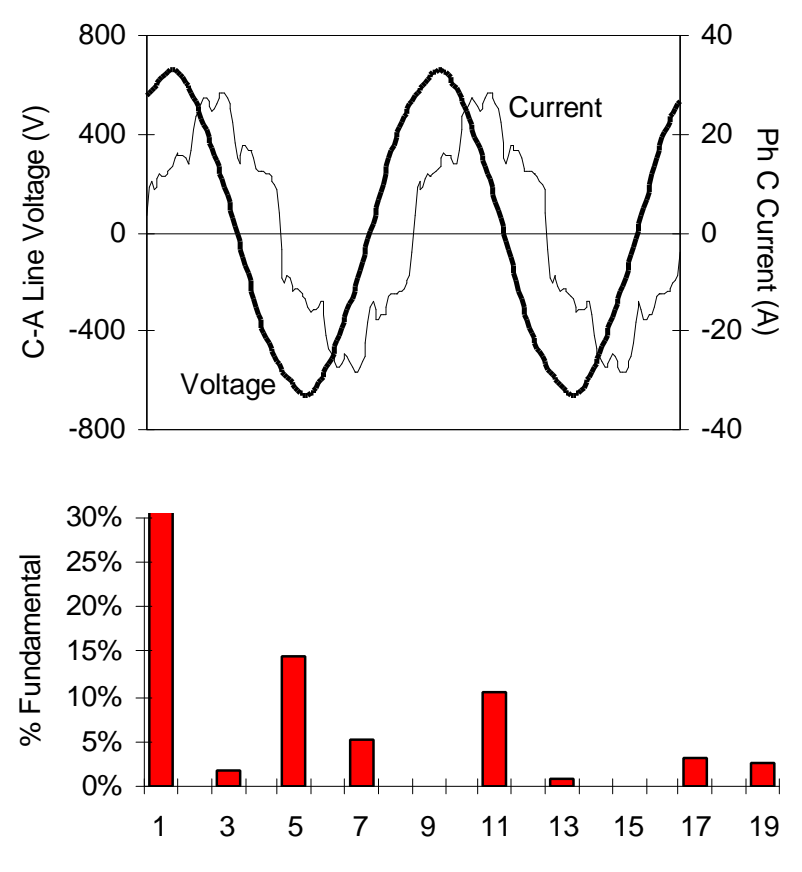

Current Harmonic Order

(a)
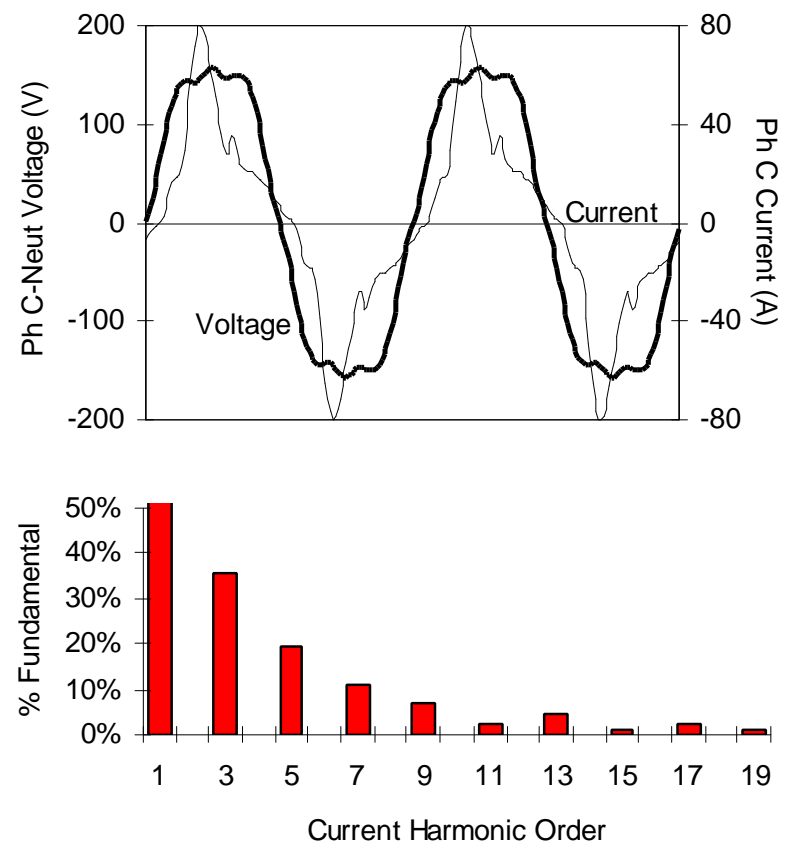

(b)

Fig. 11. Uninterruptible power supply (a) line and (b) load waveforms and current harmonic spectrum.

Although a UPS provides protection from loss of a voltage source, many on-line UPS's demand current that has considerable harmonic content and/or supply a voltage to the load that has distortion.

The UPS for which the waveforms are shown in Fig. 11 was 3-phase, $37.5 \mathrm{kVA}, 480 \mathrm{~V}$ input, and 120/208 V output. 
This particular UPS drew a line current that averaged $19.0 \%$ THD for the three phases and had an absence of triplen harmonics (Fig. 11a). The UPS input consisted of a six-pulse rectifier and a smoothing inductor which drew a line current whose harmonic spectrum consisted mostly of the 5th, 7th, 11th, 13th, 17th, and 19th harmonics.

The load current had a crest factor above 2.0 which caused the flat-topping of the voltage output as shown in Fig. 11b. The UPS output voltage waveform for each of the three phases had a distortion ranging from 8.0 to $16.8 \%$ THD. IEEE 519, Recommended Practices and Requirements for Harmonic Control in Electrical Power Systems, states that voltage distortion should not exceed 5\% at the end use loads [11]. Obviously, this UPS did not meet these requirements.

\section{Finding Harmonics Before Problems Arise}

The intent of the survey of the DOE buildings was first to determine the extent of harmonics in the facilities and secondly to apprise whether any of the locations that had a significant level of harmonics could lead to an electrical problem in the near future.

Voltage THD should be less than 5\% throughout a plant's electrical distribution system. Values above $10 \%$ should be investigated thoroughly, and some harmonic mitigation equipment will be necessary to bring the value to less than $5 \%$. The voltage THD for all of the panels surveyed at the Oak Ridge DOE plants was between $2.0 \%$ and $4.5 \%$.

Simply having a high THD for a current waveform does not necessarily pose a problem to the electrical system or other nearby connected loads. The RMS magnitude and the distribution of the harmonic spectrum are more important indicators for determining an electrical system's susceptibility to harmonics. Higher frequency harmonics are more likely to interfere with communication lines or electronically controlled equipment than harmonics which have a frequency closer to that of the line frequency. Harmonic currents also cause increased heating effects in power handling equipment such as cables, motors, and capacitors. Some of the heating effects such as skin effect are directly proportional to the frequency, and others such as eddy current losses in a transformer are proportional to frequency squared. These increased heating effects can shorten equipment operating life [1]. Circuit breakers, capacitors, and transformers which carry current that has a substantial THD (greater than 25\%) and are loaded to above $75 \%$ of their capacity should be checked to see that they are within their operating temperature limit. Load derating of the equipment may then be necessary to maintain a normal operating life.

Only one of the 200 panels surveyed at the Oak Ridge DOE plants was carrying a current greater than $75 \%$ of its listed ampacity, and only 10 were loaded greater than $50 \%$ of their rating. Of the 200 panels surveyed, 11 had current higher in the neutral than any of the phase conductors. Because the panels were not carrying their rated load, this did not pose a problem. However, if one of these 11 panels had been carrying its rated load, the neutral conductor could have easily overheated because it was sized the same as the phase conductors instead of the $200 \%$ recommended for panels with a substantial nonlinear load $[14,15]$.

\section{CONCLUSIONS}

Harmonics is an issue that has only come to the forefront in general electrical distribution design in the last few years. Because harmonics are present in all distribution systems, the quick method of measurement with two different types of multimeters and simple calculations outlined in this paper help the engineer to identify where high levels of harmonic voltages or currents may be present. The engineer can then use a more expensive and time-consuming power analyzer to examine the spectrum of harmonics present and to determine their source. The engineer must then decide whether the harmonics pose a potential hazard to the electrical system and what steps should be taken to suppress the harmonics.

\section{REFERENCES}

[1] IEEE Task Force, "Effects of harmonics on equipment", IEEE Trans. Power Delivery, vol. 8, Apr. 1993, pp. 672-680.

[2] IEEE Task Force, "The effects of power system harmonics on power system equipment and loads", IEEE Trans. Power Apparatus and Systems, vol. PAS-104, Sept. 1985, pp. 2555-2563.

[3] A. Mansoor et. al, "Predicting the net harmonic currents produced by large numbers of distributed single-phase computer loads", IEEE Trans. Power Delivery, vol. 10, Oct. 1995, pp. 2001-2006.

[4] J. Lai, D. Hurst, and T. Key, "Switch-mode power supply power factor improvement via harmonic elimination methods", Conf. Rec. Applied Power Electron. Conf. (Dallas, TX), Mar. 1991, pp. 415-422.

[5] R. Dwyer et. al, "Evaluation of harmonic impacts from compact fluorescent lights on distribution systems", IEEE Trans. Power Systems, vol. 10, Nov. 1995, pp. 1772-1779.

[6] F. V. Topalis, "Efficiency of energy saving lamps and harmonic distortion in distribution systems," IEEE Trans. Power Delivery, vol. 8, Oct. 1993, pp. 2038-2042.

[7] N. Mohan, T. M. Undeland, and W. P. Robbins, Power Electronics: Converters, Applications, and Design, John Wiley \& Sons, 1989.

[8] W. D. Stevenson, Jr., Elements of Power System Analysis, McGraw-Hill Book Company, 1980.

[9] C. Melhorn and M. McGranaghan, "Interpretation and analysis of power quality measurements", IEEE Trans. Industry Applications, vol. 31, Nov. 1995, pp. 1363-1370.

[10] L. M. Tolbert, "Harmonic Analysis of Electrical Distribution Systems," ORNL-6887, Oak Ridge National Laboratory Report, March 1996.

[11] IEEE Recommended Practices and Requirements for Harmonic Control in Electric Power Systems, IEEE Std 519-1992.

[12] A. McEachern, Handbook of Power Signatures, Basic Measuring Instruments, 1989.

[13] The Dranetz Field Handbook for Power Quality Analysis, 1991.

[14] A. Freund, "Double the Neutral and Derate the Transformer - or Else!", EC\&M, Dec. 1988, pp. 81-85.

[15] R. G. Ellis, "Harmonic analysis of industrial power systems," IEEE Trans. Industry Applications, vol. 32, Mar. 1996, pp. 417-421. 